\title{
TLR2 and TLR4 Activate p38 MAPK and JNK during Endurance Exercise in Skeletal Muscle
}

\author{
HERMANN ZBINDEN-FONCEA ${ }^{1,2}$, JEAN-MARC RAYMACKERS ${ }^{1}$, LOUISE DELDICQUE ${ }^{1,3}$, PATRICIA RENARD ${ }^{4}$, \\ and MARC FRANCAUX ${ }^{1}$ \\ ${ }^{1}$ Institute of Neuroscience, Medical Sector, Université catholique de Louvain, Louvain-la-Neuve, BELGIUM; ${ }^{2}$ School of \\ Kinesiology, Health Research Center, Faculty of Medicine, Finis Terrae University, Santiago, CHILE; ${ }^{3}$ Research \\ Centre for Exercise and Health, Department of Biomedical Kinesiology, Faculty of Kinesiology and Rehabilitation Science, \\ KU Leuven, Leuven, BELGIUM; and ${ }^{4}$ Research Unit of Cell Biology, Department of Biology, Faculty of Science, \\ University of Namur, Namur, BELGIUM
}

\begin{abstract}
ZBINDEN-FONCEA, H., J.-M. RAYMACKERS, L. DELDICQUE, P. RENARD, and M. FRANCAUX. TLR2 and TLR4 Activate p38 MAPK and JNK during Endurance Exercise in Skeletal Muscle. Med. Sci. Sports Exerc., Vol. 44, No. 8, pp. 1463-1472, 2012. Purpose: Toll-like receptors 2 and 4 (TLR2, TLR4) are found in the membrane of skeletal muscle cells. A variety of molecular components can activate TLR2 and TLR4, among others, long-chain fatty acids. The subsequent downstream signaling triggers the mitogen-activated protein kinase (MAPK) and nuclear factor- $\kappa \mathrm{B}(\mathrm{NF}-\kappa \mathrm{B})$ pathways. Therefore, the purpose of this study was to test whether an elevation of extracellular nonesterified fatty acids (NEFA) observed during endurance exercise may activate the MAPK and NF- $\kappa$ B pathways via TLR2 and TLR4. Methods: $t r 2^{-1-}$ and $t r 4^{-1-}$ mice and wild-type C57BL/6J animals (WT) were submitted to a standardized endurance exercise. Results: Immediately after exercise, the phosphorylation state of p38 MAPK, c-Jun $\mathrm{NH}_{2}$-terminal kinase (JNK), and c-Jun was increased in the tibialis anterior (TA) and soleus (SOL) muscles of WT $(P<0.05)$. The phosphorylation state of extracellular signal-regulated kinases 1 and $2($ ERK $1 / 2)$ and I $\kappa$ B kinase $\alpha / \beta$ and the DNA-binding of NF- $\kappa$ B remained unchanged. The activation of $\mathrm{p} 38 \mathrm{MAPK}$, JNK, and c-Jun was completely blunted in TA of $t r 2^{-1-}$ and $t r 4^{-/-}$mice, whereas in SOL, it represented only $25 \%$ of the increase observed in WT mice. The causal relationship between NEFA concentration and MAPK activation was evaluated by injecting mice with heparin. A similar increase in plasma NEFA was observed after heparin injection than after endurance exercise. JNK and p38 MAPK were activated under heparin in TA and SOL of WT $(P<0.05)$ but not in muscles of $t l r 2^{-/-}$and $t l r 4^{-/-}$mice. Conclusions: The present study supports the idea that during endurance exercise, TLR2 and TLR4 mediate a signal linking the elevated plasma NEFA concentration to the activation of p38 MAPK and JNK. Key Words: NF- $\kappa$ B, FATTY ACIDS, HSP70, LPS
\end{abstract}

$\mathrm{E}$ ndurance exercise results in an increased extracellular level of nonesterified fatty acids (NEFA), which contributes to energy expenditure depending on the relative power output and duration of exercise. Several reports have suggested that beside their role in energy supply for skeletal muscle, NEFA could also play a role in activating signaling pathways that regulate gene expression $(7,16,35)$.

Toll-like receptors (TLR) are transmembrane proteins that detect a variety of molecular components. To date, 11 members of the TLR family have been identified in humans, and 13 have been identified in mice (27). TLR are highly

Address for correspondence: Marc Francaux, Ph.D., Place Pierre de Coubertin 1, bte L8.10.01, 1348 Louvain-la-Neuve, Belgium; E-mail: marc.francaux@ uclouvain.be.

Submitted for publication September 2011.

Accepted for publication January 2012.

0195-9131/12/4408-1463/0

MEDICINE \& SCIENCE IN SPORTS \& EXERCISE E $_{\circledast}$

Copyright (C) 2012 by the American College of Sports Medicine

DOI: 10.1249/MSS.0b013e31824e0d5d expressed in cells of the innate immune system, but TLR2 and TLR4 are also found in various other cell types including myocytes (30). TLR2 and TLR4 bind specific ligands, the best described being FSL-1 (Pam2Cys-GDPKHPKSF) and peptidoglycan for TLR2 and lipopolysaccharide (LPS) for TLR4. Other ligands such as heat shock protein $70 \mathrm{kDa}$ (HSP70) can bind both TLR2 and TLR4 (2). NEFA are also able to activate them, although direct binding between NEFA and TLR2 and TLR4 remains uncertain (12). NEFA have been shown to activate TLR2 in C2C12 myogenic cells (32) and TLR4 in the RAW264.7 macrophage cell line and in 3T3-L1 preadipocytes (33). These observations suggest that elevated levels of NEFA in the extracellular space could trigger the TLR-mediated signaling pathways. On this basis, we hypothesized that an increase in plasma NEFA concentration observed during endurance exercise might activate intracellular signaling cascades through TLR2 and/or TLR4.

Upon stimulation, TLR2 and TLR4 recruit interleukin 1 receptor type 1-associated protein kinases via adaptors such as the myeloid differentiation primary response gene 88 and toll-interleukin 1 receptor domain-containing adapter protein 
(1). TLR4 is also capable of inducing a myeloid differentiation primary response gene 88 -independent pathway in which the toll interleukin-1 receptor domain-containing adapter-inducing interferon- $\beta$ and toll interleukin- 1 receptor domain-containing adapter-inducing interferon- $\beta$ related adaptor molecule play the role of adaptors (1). Both signaling pathways lead to the activation of the mitogenactivated protein kinase (MAPK) family and transcription factors including nuclear factor- $\kappa \mathrm{B}(\mathrm{NF}-\kappa \mathrm{B})(1)$.

The results available in the literature regarding the activation of NF- $\kappa \mathrm{B}$ pathways during exercise are equivocal. On the one hand, an increased phosphorylation state of IKK (I $\kappa$ B kinase), a kinase upstream of NF- $\kappa \mathrm{B}$, has been observed in rat skeletal muscle during a 60-min submaximal exercise, whereas NF- $\kappa$ B activity increased only $1-3 \mathrm{~h}$ after the completion of exercise (15). In contrast, fatiguing muscle contractions have been shown to diminish NF- $\kappa$ B activity in both humans and mice (11). Another study showed no changes in NF- $\kappa$ B protein level $1 \mathrm{~h}$ after a $2-\mathrm{h}$ run at $65 \%$ of $\dot{\mathrm{VO}}_{2 \max }$ in rats (22).

The MAPK family is composed of four distinct governing members: 1) extracellular signal-regulated kinases (ERK) 1 and 2 (ERK1/2), 2) p38 MAPK, 3) c-Jun $\mathrm{NH}_{2}$-terminal kinases (JNK), and 4) ERK5 or big MAPK. With the exception of ERK5, all MAPK are known to be activated by exercise (for review, see Kramer and Goodyear [18]). They participate in the regulation of metabolism, cell proliferation, differentiation, and growth by regulating transcription factors and coactivators (18). The mechanisms by which $\mathrm{p} 38$ MAPK, JNK, and ERK1/2 are activated during exercise are not fully understood. Local mechanisms of activation could be implicated, such as reactive oxygen species, cell acidification, and mechanical perturbations (18). In addition to those general mechanisms, MAPK undergoing memberspecific regulations could be involved. For example, in an animal model, the phosphorylation state of p38 MAPK and JNK increases during endurance exercise, whereas the activation of ERK1/2 is not affected (36).

Exercise regulates various signaling pathways and the expression of related genes depending on exercise intensity, duration, and paradigm, as well as the dietary status. For example, glucose ingestion during endurance exercise modifies the whole-body substrate flux, causing a decrease in plasma NEFA levels and modifying exercise-induced expression of fat oxidative genes (7). Administration of acipimox (5carboxy-2-methyl-1-oxidopyrazin-1-ium), a niacin derivative used as a hypolipidemic drug, reduced both $\beta$-adrenergicinduced fat oxidation and muscle uncoupling protein 3 messenger RNA levels, suggesting a role of NEFA in the regulation of gene expression (16). This was confirmed by cell culture experiments in which gene expression of L6 cells was modified when incubated with palmitate (35).

Taken together, these data indicate that extracellular NEFA may regulate signaling pathways implicated in gene expression. This is important for the understanding of the molecular mechanisms that lead to muscle adaptation during an endur- ance exercise program. Because NEFA have been shown to activate TLR in myogenic cell culture models, we tested in the present study the hypothesis that the elevated plasma NEFA concentration observed during endurance exercise may activate the MAPK and the NF- $\kappa$ B pathways via a signal transduced by TLR 2 and TLR4. The results provide evidence that plasma NEFA participate in the activation of p38 MAPK and JNK observed after treadmill exercise in mice via a mechanism implicating TLR2 and TLR4.

\section{METHODS}

\section{Animals}

Male C57BL/6J mice (12-14 wk) were housed under standard laboratory conditions (12:12-h light-dark cycle) and provided with water and food ad libitum. tlr $2^{-1-}$ (24) and tlr $4^{-1-}$ mice (17) were purchased from the Transgenose Institute, Centre National de la Recherche Scientifique Orleans, France. Animals were systematically genotyped for verifying deletion of genes coding for TLR2 or TLR4. All protocols were approved by the ethical committee for animal use of the Université catholique de Louvain (Belgium), and the housing conditions were as specified by the Belgian Law of November 14, 1993, on the protection of laboratory animals (agreement number LA 1220548). The animals were housed in accordance with the American College of Sports Medicine standards for animal care.

\section{Exercise Protocol}

Thirty-six mice, including wild-type (WT, $n=12$ ), $t \operatorname{tr} 2^{-/-}$ $(n=12)$, and $t r 4^{-1-}(n=12)$ mice, were familiarized with treadmill exercise by running for $20 \mathrm{~min}\left(8-12 \mathrm{~m} \cdot \mathrm{min}^{-1}\right)$ on two successive days. On the third day, mice were submitted to an incremental exercise test. The starting velocity was $8 \mathrm{~m} \cdot \mathrm{min}^{-1}$ and was increased by $2 \mathrm{~m} \cdot \mathrm{min}^{-1}$ every $2 \mathrm{~min}$ until exhaustion. The maximal velocity $\left(V_{\max }\right)$ was defined as the velocity of the last stage completed by the animals. No interventions were programmed on the next day. Afterward, the animals were kept fasted $12 \mathrm{~h}$ overnight. Eighteen animals (WT: $n=6$, tlr $2^{-l-}: n=6$, and $t l r 4^{-l-}: n=6$ ) were kept at rest (nonrunners), whereas the others (runners) were submitted to an endurance exercise protocol previously used by others (34). It consisted in two bouts of 60-min running at $70 \%$ of $V_{\max }$. The two bouts were separated by a $30-\mathrm{min}$ recovery period. This exercise protocol was chosen because it was reported to enhance adipose tissue lipolysis (34). Immediately after exercise completion, the animals were anesthetized by an intraperitoneal injection of a solution $\left(4 \mathrm{~mL} \cdot \mathrm{kg}^{-1}\right)$ containing ketamine $\left(40 \mathrm{mg} \cdot \mathrm{mL}^{-1}\right)$ and xylazine $\left(4 \mathrm{mg} \cdot \mathrm{kg}^{-1}\right)$ to preserve muscle circulation during dissection. The depth of anesthesia was assessed by the disappearance of the eyelid, corneal, and pedal withdrawal reflexes. The soleus (SOL) and tibialis anterior (TA) muscles were rapidly removed, frozen in liquid nitrogen, and stored at $-80^{\circ} \mathrm{C}$ until subsequent analyses. The duration of the procedure including the anesthesia was about $5 \mathrm{~min}$; this short delay should not have affected 
the state of phosphorylation of the studied proteins as blood circulation was maintained. Blood samples were collected through heart puncture by using syringes containing EDTA and immediately centrifuged for $10 \mathrm{~min}$ at $1500 \mathrm{~g}$. Plasma was kept frozen at $-80^{\circ} \mathrm{C}$. After dissection, the animals were killed by rapid neck dislocation.

\section{Lipolysis Stimulation by Heparin}

After an overnight fast, 18 mice (WT, $t$ lr $2^{-1-}$, or tlr $4^{-1-}$, $n=6$ in each group) were injected with $2000 \mathrm{U} \cdot \mathrm{kg}^{-1}$ of heparin (Heparin LEO $^{\circledR}$; Leo Pharma, Wilrijk, Belgium) intraperitoneally. Pilot experiments had been conducted to determine the dose required to induce a plasma NEFA concentration similar to the one observed after the endurance exercise protocol. The same number of animals was injected with a saline solution. After $150 \mathrm{~min}$, the animals were anesthetized. Muscles and blood samples were collected following the same procedure as described above.

\section{Lipopolysaccharide Injection}

Eighteen mice were injected with $8 \mathrm{mg} \cdot \mathrm{kg}^{-1}$ of Ultrapure LPS (InvivoGen, Toulouse, France) (WT, tlr $2^{-/-}$, and tlr $4^{-1-}, n=3$ in each strain) or with a saline solution (WT, $t l r 2^{-1-}$, and $t l r 4^{-1-}, n=3$ in each strain). Blood samples and muscles were collected after $120 \mathrm{~min}$.

\section{Analysis of Blood Samples}

Plasma NEFA concentration was determined using a kit coupling enzymatic reaction and spectrophotometric detection $(550 \mathrm{~nm})$ of the reaction end product (Wako, Neuss, Germany). Plasma HSP70 concentration was determined by an enzyme-linked immunosorbent assay kit (Biocompare, Brussels, Belgium) according to the instructions of the manufacturer.

\section{Analysis of Muscle Samples}

Preparation of muscle lysates. Muscles were ground by using a pestle (Bel-Art Products, Pequannock, NJ) and homogenized in an ice-cold lysis buffer containing $20 \mathrm{mM}$ of Tris, $\mathrm{pH} 7.0 ; 270 \mathrm{mM}$ of sucrose; $5 \mathrm{mM}$ of ethyleneglycotetraacetic acid; $1 \mathrm{mM}$ of EDTA; $1 \%$ Triton X-100 (Sigma-Aldrich, Bornem, Belgium); $1 \mathrm{mM}$ of sodium orthovanadate; $50 \mathrm{mM}$ of sodium $\beta$-glycerophosphate; $5 \mathrm{mM}$ of sodium pyrophosphate; $50 \mathrm{mM}$ of sodium fluoride; $1 \mathrm{mM}$ of 1,4-dithiothreitol; and a protease inhibitor cocktail (Roche Applied Science, Vilvoorde, Belgium). Muscle homogenates were centrifuged at $10,000 \mathrm{~g}$ for $15 \mathrm{~min}$ at $4^{\circ} \mathrm{C}$. Protein concentration was determined using a DC protein assay kit (BioRad Laboratories, Nazareth, Belgium) with bovine serum albumin as a standard. Muscle lysates were stored at $-80^{\circ} \mathrm{C}$ until subsequent analyses.

Nuclear proteins were extracted using the method described by Deldicque et al. (10). Muscles were ground and then harvested in a hypotonic buffer containing $20 \mathrm{mM}$ of HEPES, $5 \mathrm{mM}$ of sodium fluoride, $1 \mathrm{mM}$ of sodium mo- lybdate, $0.1 \mathrm{mM}$ of EDTA, and $0.5 \%$ IGEPAL CA-630 (Nonidet P-40)(Sigma-Aldrich). Homogenates were centrifuged for $30 \mathrm{~s}$ at $10,000 \mathrm{~g}$. The pellet was resuspended in a buffer containing $20 \mathrm{mM}$ of HEPES, $5 \mathrm{mM}$ of sodium fluoride, $1 \mathrm{mM}$ of sodium molybdate, $0.1 \mathrm{mM}$ of EDTA, $20 \%$ glycerol, and a protease inhibitor cocktail (Roche Applied Science), to which the same volume of a saline buffer containing $20 \mathrm{mM}$ of HEPES, $5 \mathrm{mM}$ of sodium fluoride, $1 \mathrm{mM}$ of sodium molybdate, $0.1 \mathrm{mM}$ of EDTA, $20 \%$ glycerol, $0.8 \mathrm{M}$ of $\mathrm{NaCl}$, and a protease inhibitor cocktail (Roche Applied Science) was added. The solution was mixed for $30 \mathrm{~min}$ at $4^{\circ} \mathrm{C}$ and centrifuged for $10 \mathrm{~min}$ at $10,000 \mathrm{~g}$. The supernatant was removed and stored at $-80^{\circ} \mathrm{C}$. Protein concentration was determined as described above.

Western blotting. Protein lysates $(25-50 \mu \mathrm{g})$ were combined with Laemmli buffer and separated by sodium dodecyl sulfatepolyacrylamide gel electrophoresis $(10 \%-12 \%)$. After electrophoretic separation $(40 \mathrm{~mA})$, the proteins were transferred to polyvinylidene fluoride membranes at $80 \mathrm{~V}$ for $2 \mathrm{~h}$. Membranes were blocked for $60 \mathrm{~min}$ in Tris-buffered saline with $0.1 \%$ Tween 20 (TBST) and 5\% nonfat dried milk. Then, the membranes were incubated overnight at $4^{\circ} \mathrm{C}$ in TBST containing $1 \%$ bovine serum albumin and one of the following antibodies: p38 MAPK (1:1000), phospho-p38 MAPK Thr180/Tyr182 (1:1000), stress-activated protein kinase (SAPK)/JNK (1:1000), phospho-SAPK/JNK Thr183/Tyr185 (1:750), ERK1/2 (1:1000), phospho-ERK1/2 Thr202/Tyr204 (1:1000), IKK $\alpha$ (1:1000), phospho-IKK $\alpha / \beta$ Ser176/180 (1:1000), c-Jun (1:1000), phospho-c-Jun Ser63 (1:1000), $\mathrm{I} \kappa \mathrm{B} \alpha$ (1:1000), and glyceraldehyde 3-phosphate dehydrogenase (GAPDH) (1:10,000). All antibodies were obtained from Cell Signaling Technology (Leiden, The Netherlands) except GAPDH, which was from Abcam (Cambridge, United Kingdom). Membranes were washed three times with TBST and were incubated with a secondary antibody at room temperature for $60 \mathrm{~min}$ (antirabbit $(1: 10,000)$ or antimouse $(1: 20,000)$ from Sigma (Bornem, Belgium)). After three additional washes, chemiluminescent detection was carried out using an ECL Western blotting kit (Amersham ECL Plus; GE Healthcare, Diegem, Belgium). Bands were visualized on film, scanned, and quantified by densitometry using the ImageMaster 1D image analysis software (Amersham-GE Healthcare, Diegem, Belgium). Results are reported as the ratio of the signal induced by the protein of interest divided by the signal induced by GAPDH.

DNA binding of NF $-\kappa$ B. DNA binding of NF $-\kappa$ B was measured as described by Renard et al. (29). Ninety-six-well plates were coated with a double-stranded oligonucleotidic probe containing the consensus binding for NF- $\kappa \mathrm{B}$. Muscle lysate containing nuclear proteins $(35 \mu \mathrm{g})$ was placed in the wells and incubated for $1 \mathrm{~h}$ at room temperature. Then, the wells were washed three times with a phosphate-buffered saline (PBS) solution (phosphate $=10 \mathrm{mM}, \mathrm{NaCl}=50 \mathrm{mM}$, $\mathrm{pH}=7.5$ ) containing $0.1 \%$ Tween. Rabbit anti-NF- $\kappa \mathrm{Bp} 65$ (100 $\mu \mathrm{L}$; Santa Cruz, Boechout, Belgium) diluted 1000 times in a PBS-10 solution (phosphate $=10 \mathrm{mM}, \mathrm{NaCl}=10 \mathrm{mM}$, 
TABLE 1. Body mass and maximal running velocity $\left(V_{\max }\right)$ in WT and transgenic t/r2 ${ }^{-1-}$ or $\mathrm{Ir}^{-/-}$mice.

\begin{tabular}{lcc}
\hline & Body Mass $(\mathbf{g})$ & $\boldsymbol{V}_{\max }\left(\mathbf{m} \cdot \mathbf{m i n}^{-\mathbf{1}}\right)$ \\
\hline WT & $24.4 \pm 0.83$ & \\
$\quad$ Nonrunners & $26.1 \pm 0.57$ & $19.0 \pm 1.34$ \\
$\quad$ Runners \\
$t / r 2^{-/-}$ & $24.4 \pm 0.27$ & $18.0 \pm 1.15$ \\
$\quad$ Nonrunners & $23.2 \pm 0.66$ & $19.3 \pm 1.60$ \\
$\quad$ Runners \\
$t / r 4^{-/-}$
\end{tabular}

$1 \%$ nonfat dried milk, $\mathrm{pH}=7.5$ ) was added in each well for $1 \mathrm{~h}$ at room temperature. The wells were washed three times. Subsequently, $100 \mu \mathrm{L}$ of a peroxidase-conjugated goat antirabbit immunoglobulin G (Santa Cruz) diluted 1000 times in a PBS-10 solution was added in each well for $1 \mathrm{~h}$ at room temperature. After three additional washes, tetramethylbenzidine (100 $\mu \mathrm{L}$; BioSource, Nivelles, Belgium) was added in the wells and incubated for $10 \mathrm{~min}$ at room temperature before adding $100 \mu \mathrm{L}$ of stopping solution (BioSource). Optical density was read at $405 \mathrm{~nm}$ using a $655-\mathrm{nm}$ reference wavelength with a Benchmark Microplate Reader (Bio-Rad Laboratories).

\section{Statistical Analysis}

All results are presented as means \pm SEM. The significance of differences observed between means was inferred by a two-way ANOVA design wherein mice strains and treatment were the independent factors. When appropriate, Bonferroni post hoc tests were applied. Testing for outliers was done with the Grubbs test (20). No more than one sample was rejected in each series. The signification threshold was set to $P<0.05$.

\section{RESULTS}

Body weight and exercise performance. Baseline characteristics such as body weight and $V_{\max }$ were similar between WT and transgenic tlr $2^{-1-}$ and $t l r 4^{-1-}$ mice. Likewise, body weight and $V_{\max }$ were not different between runner and nonrunner mice, before training (Table 1).

Plasma NEFA concentration. Plasma NEFA concentration was similar in all mice kept at rest (Figs. 1A, B). Higher plasma NEFA concentration was observed after exercise $(P<0.001)$ (Fig. 1A). NEFA level was more than doubled after exercise in WT and increased even more in $t l r 2^{-/-}(P=0.007)$ and in $t l r 4^{-1-}(P=0.019)$ in comparison with WT mice, although the interaction between strain and treatment did not reach statistical significance $(P=0.093$; Fig. 1A).

Heparin (2000 U $\mathrm{kg}^{-1}$, intraperitoneally) was injected to WT and transgenic $t l r 2^{-1-}$ and $t l r 4^{-1-}$ mice, whereas a control group was injected with an equal volume of sterile saline. Heparin injection induced an increase in plasma NEFA concentration of about $290 \%$ (Fig. 1B) in all strains.

HSP70 is a TLR ligand that can be increased during exercise (26) and could potentially influence the present results.
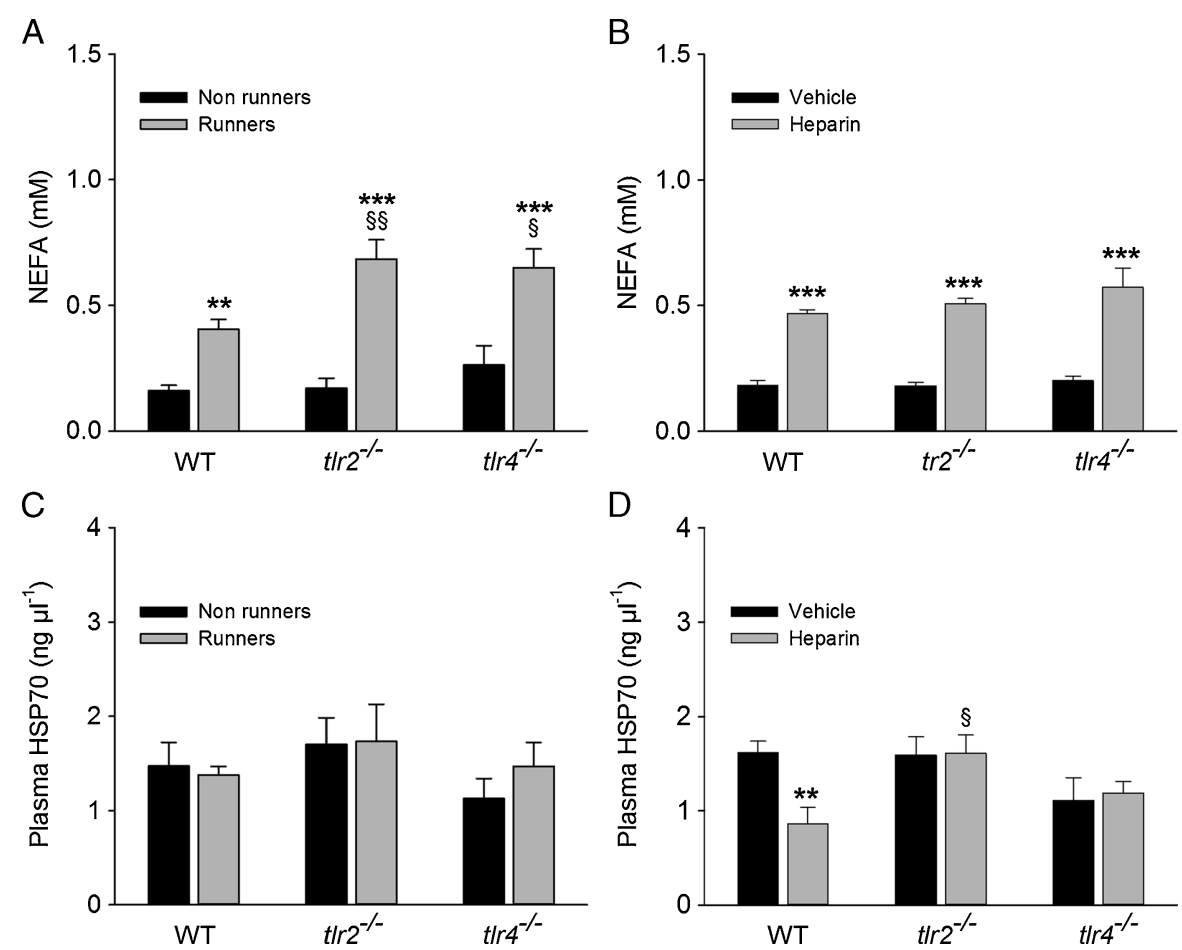

FIGURE 1-NEFA and HSP70 concentrations after exercise or heparin-induced lipolysis. Significant differences between runner and nonrunner mice (A and $C$ ) or between heparin- and vehicle-treated mice (B and D) from the same strain are indicated as follows: $* * P<0.01$ and $* * * P<0.001$. Significant differences between WT and $t \mathrm{tr} 2^{-1-}$ or tlr $4^{-1-}$ mice are indicated as follows: $\S P<0.05$ and $\S \S P<0.01$. $n=5-6$ for each $h i s t o g r a m$. 

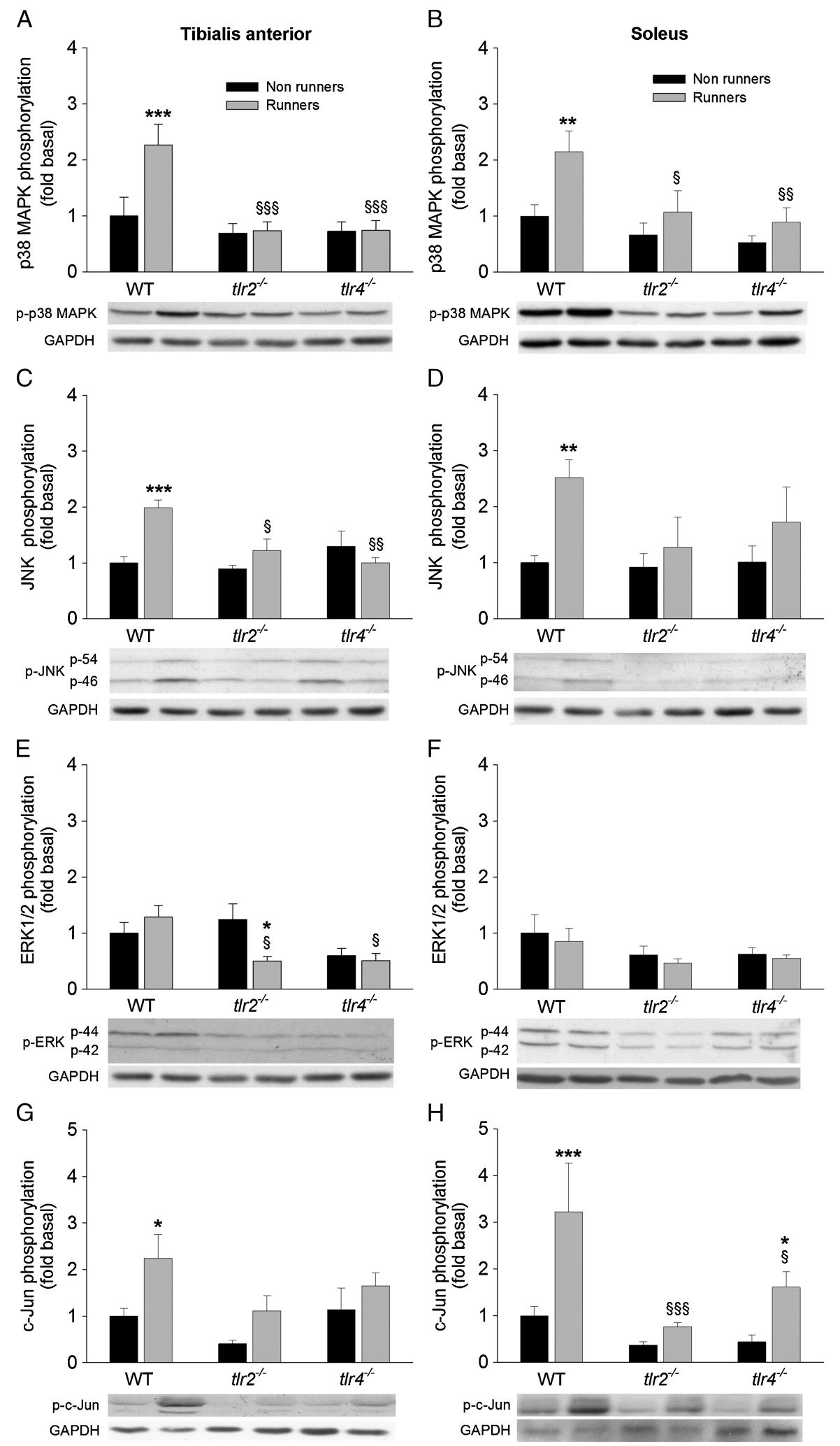

FIGURE 2-Exercise-induced phosphorylation states of MAPK. Significant differences between mice from the same strain are indicated as follows: *P< $0.05, * * P<0.01$, and $* * * P<0.001$. Significant differences between WT and $t r 2^{-l-}$ or $t r 4^{-1-}$ mice are indicated as follows: $\S P<0.05, \S \S P<0.01$, and $\S \S \S<0.001 . n=5-6$ for each histogram. 
None of the experimental strategies produced any increase in plasma HSP70 concentrations, either in WT or in $t l r 2^{-/-}$or tlr $4^{-/-}$(Figs. 1C, D).

Implication of TLR2 and TLR4 in p38 MAPK, JNK, and c-Jun activation by endurance exercise. In SOL and TA, the level of total p38, ERK, and JNK was affected neither by genetics nor by exercise. In $t l r 4^{-1-}$ animals, there was a slight but nonsignificant decrease in total p38 (data not shown). At rest, the phosphorylation states of p38 MAPK, JNK, and ERK1/2 were similar between strains both in TA and in SOL (Fig. 2). In WT, endurance exercise resulted in a higher phosphorylation state of p38 MAPK $(+2.3 \pm 0.40$ fold, $P=0.001$; Fig. 2A) and JNK $(+2.0 \pm 0.1$-fold, $P<$ 0.001 ; Fig. $2 \mathrm{C}$ ) in TA. JNK and p38 MAPK activations elicited by endurance exercise were repressed in $t l r 2^{-1-}$ and tlr $4^{-1-}$ transgenic mice (strain $\times$ treatment for $\mathrm{p}$-p38 MAPK: $P=0.030$, strain $\times$ treatment for $\mathrm{p}-\mathrm{JNK}: P=0.004$; Figs. $2 \mathrm{~A}$, C). In WT SOL, endurance exercise increased the phosphorylation state of p38 MAPK $(+2.1 \pm 0.4$-fold, $P=0.006$; Fig. $2 \mathrm{~B})$ and $\mathrm{JNK}(+2.5 \pm 0.3$-fold, $P=0.008$; Fig. $2 \mathrm{D})$, whereas in $t l r 2^{-1-}$ and $t l r 4^{-1-}$ transgenic mice, the activation was largely repressed without reaching the statistical threshold (Figs. 2B and D). Both in TA and in SOL, the phosphorylation state of ERK1/2 was not affected by the exercise protocol
(Figs. 2E and F). In WT mice, c-Jun, a target of JNK, was more phosphorylated after exercise in both the TA $(2.3 \pm$ 0.5 -fold, $P=0.023)$ and SOL $(3.2 \pm 1.0$-fold, $P<0.001)$ muscles (Figs. 2G, H). No significant increase in phosphorylation was seen either in $t l r 2^{-1-}$ or in $t l r 4^{-1-}$ muscles at rest, whereas in $t l r 4^{-1-}$ SOL, a 3.7-fold raise in c-Jun phosphorylation was observed after exercise $(P<0.05$; Fig. $2 \mathrm{H})$.

Activation of p38 MAPK and JNK by heparin through TLR2 and TLR4 receptors. Heparin is known to stimulate NEFA release in plasma (9). To assess whether a higher level of circulating NEFA may initiate the activation of p38 MAPK and JNK, heparin $\left(2000 \mathrm{U} \cdot \mathrm{kg}^{-1}\right.$, intraperitoneally) was injected into WT and transgenic $t l r 2^{-1-}$ and $t l r 4^{-1-}$ mice.

In TA of WT mice, heparin increased the phosphorylation states of p38 MAPK $(+2.6 \pm 0.5$-fold, $P<0.001$; Fig. $3 \mathrm{~A})$ and JNK $(+2.2 \pm 0.4$-fold, $P=0.001$; Fig. $3 \mathrm{C})$. In transgenic $t l r 2^{-1-}$ and $t l r 4^{-1-}$, these activations were not detectable (strain $\times$ treatment: $P=0.004)$. Similar results were found in the SOL muscle (strain $\times$ treatment: $P=0.038$ ). In the WT group, the phosphorylation state of $\mathrm{p} 38$ MAPK increased by $3.2 \pm 0.8$-fold $(P=0.01$; Fig. $3 \mathrm{~B})$, and JNK phosphorylation was significantly increased by $2.1 \pm 0.5$-fold $(P=0.022$; Fig. 3D) above basal levels. As observed in TA, transgenic
A

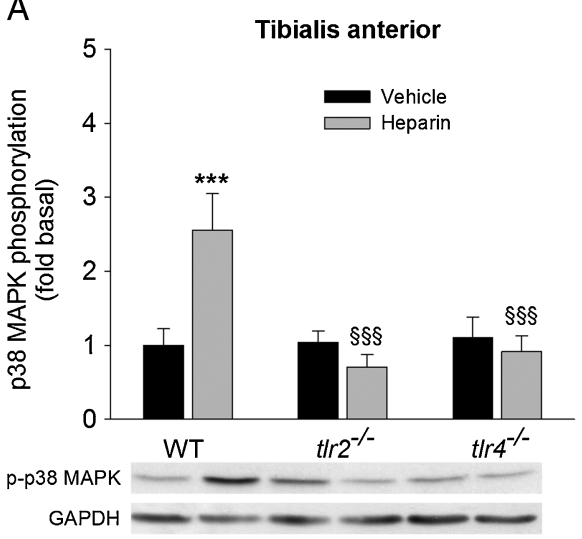

C
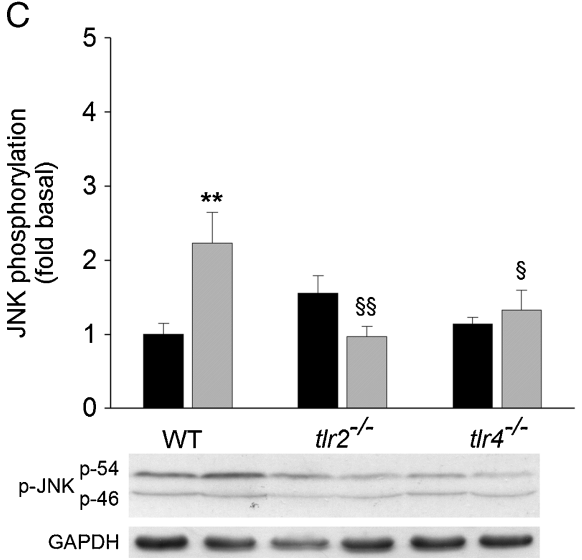

B

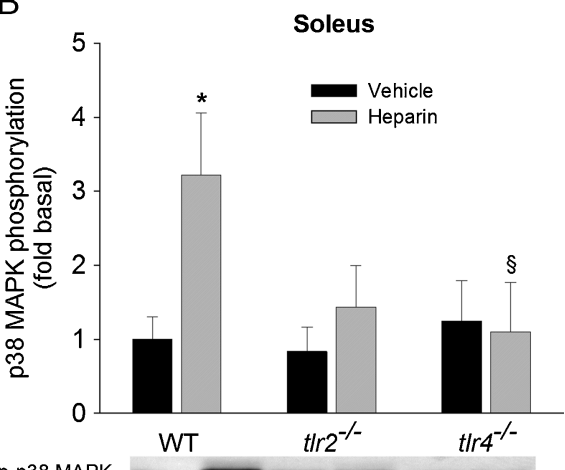

p-p38 MAPK

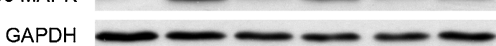

$\mathrm{D}$

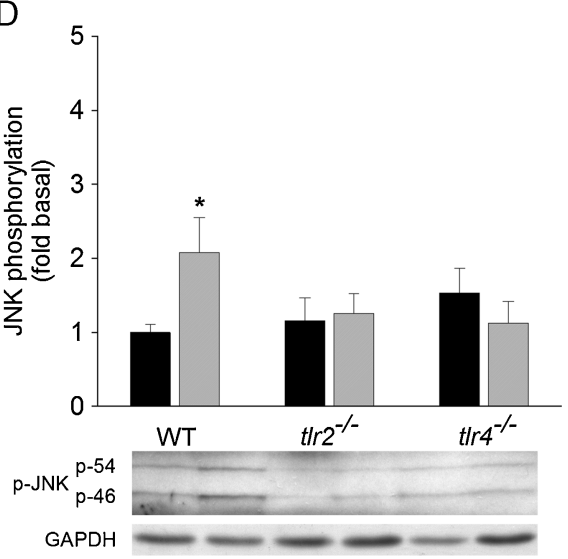

FIGURE 3-Heparin-induced phosphorylation states of MAPK. Significant differences between saline- and heparin-injected animals from the same strain are indicated as follows: ${ }^{*} P<0.05, * * P<0.01$, and $* * * P<0.001$. Significant differences between WT and $t$ lr $2^{-l-}$ or $t$ tr $4^{-1-}$ heparin-injected mice are indicated as follows: $\S P<0.05, \S \S P<0.01$, and $\S \S P<0.001 . n=5-6$ for each histogram. 
tlr $2^{-1-}$ and $t l r 4^{-1-}$ mice did not show any change in the phosphorylation state of p38 MAPK and JNK in the SOL muscle.

Heparin injection did not modify either the phosphorylation state of IKK $\alpha / \beta$ or the phosphorylation state of ERK $1 / 2$ (data not shown).

No effect of exercise on NF-кB pathway. Several techniques were used to assess the activation of the NF$\kappa \mathrm{B}$ pathway in skeletal muscle exposed to high levels of NEFA in mouse. In resting conditions, both the total form of IKK $\alpha$ (data not shown) and the phosphorylation form were

A

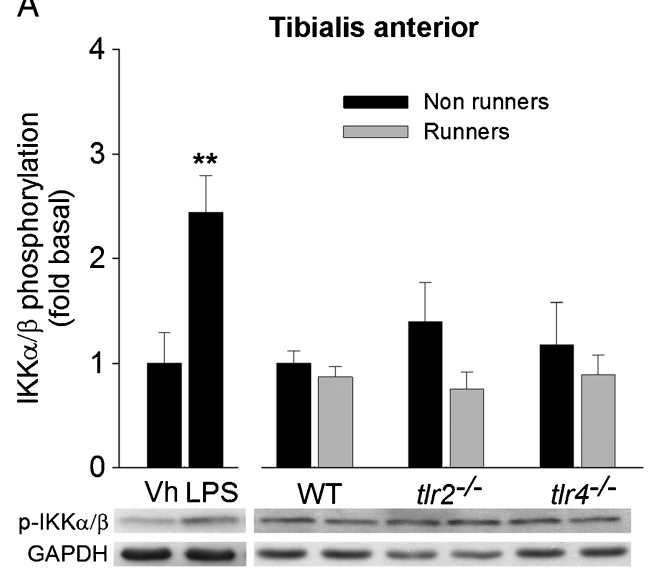

B

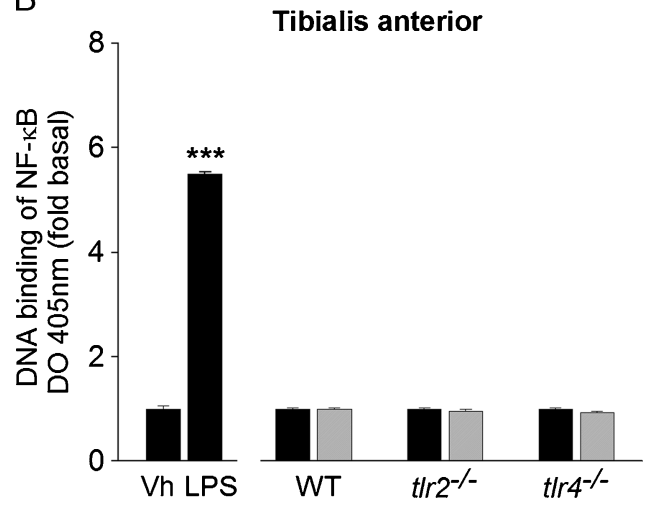

C

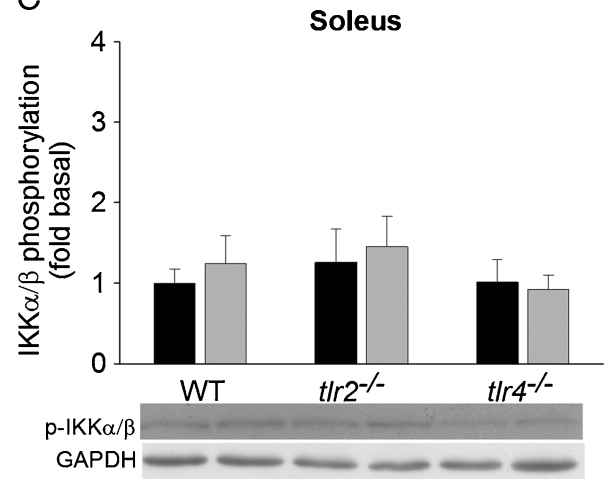

FIGURE 4-Lack of exercise-induced activation of the NF- $\mathrm{B}$ pathway. Significant differences with vehicle are indicated as follows: $* * P<$ 0.01 and $* * * P<0.001 . n=5-6$ for each histogram, except for vehicle and LPS $(n=3)$. similar in WT and in $t l r 2^{-1-}$ and $t l r 4^{-1-}$ transgenic mice in TA (Fig. 4A) and SOL (Fig. 4C). The exercise protocol did not modify the phosphorylation state of IKK $\alpha / \beta$.

To further ascertain that the NF- $\kappa \mathrm{B}$ pathway was not activated by exercise, the DNA binding of NF- $\kappa \mathrm{B}$ was measured. In the TA muscle, the DNA binding of NF- $\kappa \mathrm{B}$ was not different between strains and was not affected by the exercise protocol (Fig. 4B). WT mice treated with $8 \mathrm{mg} \cdot \mathrm{kg}^{-1}$ of LPS for $120 \mathrm{~min}$ were used as a positive control. In TA, the phosphorylation state of IKK $\alpha / \beta$ was more than doubled (Fig. 4A), and the DNA binding of $\mathrm{NF}-\kappa \mathrm{B}$ increased approximately fivefold compared with control conditions where mice were injected with a vehicle (Fig. 4B).

\section{DISCUSSION}

This study is the first to unravel the role of TLR2 and TLR4 in the activation of p38 MAPK and JNK during endurance exercise in mice. Lipids are among the multiple ligands recognized by TLR $(32,33)$. Although a direct activation of TLR by NEFA remains controversial $(12,33)$, our data support the idea that during exercise, p38 MAPK and JNK activation might be related to circulating NEFA. TLR2 and TLR 4 could thus play a role of signal transducer between extracellular NEFA and p38 MAPK and JNK activation.

Activation of p38 MAPK. Several studies have shown that MAPK signaling can increase in response to muscle contraction in the complete absence of systemic factors. Evidence from studies on isolated muscle preparations show that $\mathrm{p} 38$ MAPK activation may be triggered by calcium/calmodulindependent protein kinase II, suggesting that the increase in cytosolic calcium concentration in skeletal muscle during exercise might mediate the exercise-induced p38 MAPK activation (40). Stretch, production of reactive oxygen species, and glycogen depletion are other factors potentially involved in the activation of p38 MAPK during endurance exercise $(4,5,8)$. Previous experiments made on cell cultures and ex vivo muscle preparations indicate that MAPK could be activated by electrical, mechanical, or chemical conditions without the need of NEFA (14). However, Widegren et al. (38) showed that a 30-min onelegged exercise induced a 2.2-fold increase in p38 MAPK phosphorylation in muscles from both exercised and unexercised legs, indicating that p38 MAPK is sensitive to systemic agents. This was not the case for ERK1/2, which presented an increased phosphorylation in the exercised leg only.

Activation of JNK. Activation of JNK seems particularly sensitive to stretch because eccentric contractions induce a larger activation of JNK than concentric contractions (3). The results of the present study reveal that the signaling cascades initiated by TLR2 and TLR4 are major players of p38 MAPK and JNK activation during running endurance exercise in mice. The transgenic animals showed an almost complete repression of the increase in p38 MAPK and JNK phosphorylation in TA. In SOL of transgenic mice, 
the increase in p38 MAPK and JNK phosphorylation was not completely repressed but represented only $25 \%$ of the increase observed in WT mice.

SOL and TA were selected because they contain most slow- and fast-twitch fibers, respectively (28). Thereby, we aimed at exploring a potential fiber type-specific response, but SOL is definitely more recruited than TA during running exercise in rodents. Therefore, TLR-independent mechanisms of p38 MAPK and JNK activation should be more visible in SOL than in TA. However, they remained quantitatively lower than the TLR-dependent mechanisms, which qualify thus as main regulators of p38 MAPK and JNK activation during endurance running exercise in mice.

The MAPK activation modulates various transcription factors that are implicated in the adaptation to exercise training. To verify if increased phosphorylation of MAPK reflects higher kinase activity, we also measured c-Jun, a transcription factor downstream of JNK, in SOL and TA muscles from exercised mice. In WT animals, c-Jun was more phosphorylated after exercise, confirming the higher activity of JNK. In SOL of $t l r 2^{-1-}$ and $t l r 4^{-1-}$ mice, JNK tended to be more phosphorylated after running, which is in line with a higher phosphorylation state of c-Jun in those mice, reaching the statistical threshold in $t l r 4^{-1-}$ mice. This might suggest that small nonsignificant increases in phospho-JNK are able to activate c-Jun, although we may not rule out that other kinases, such as cyclin-dependent kinase-3 (6), were involved in the increase in phospho-c-Jun in $t$ lr $4^{-1-}$ mice after exercise.

Activation of p38 and JNK by NEFA. To rule out any confounding effect of other exercise-induced factors, we injected animals with heparin, a well-known activator of lipolysis (9), with the goal of increasing NEFA concentration at rest. After heparin injection, the phosphorylation state of p38 MAPK and JNK was increased in WT animals to similar levels as during exercise, i.e., two- to threefold. However, the increase in phosphorylation of p38 MAPK and JNK under these conditions was completely repressed in $t l r 2^{-1-}$ and $t l r 4^{-1-}$ mice in both TA and SOL. This reinforces the suggestion that the incomplete repression of $\mathrm{p} 38$ MAPK and JNK activation observed in SOL of $t l r 2^{-1-}$ and $t l r 4^{-1-}$ mice after exercise is probably due to TLRindependent mechanisms. Although heparin increases plasma NEFA concentration, the MAPK activation observed after heparin injection does not certify a causal relationship. Nevertheless, the lack of MAPK activation in transgenic mice highlights the essential role for TLR in the increased phosphorylation state of p38 MAPK and JNK. Plasma NEFA concentration is also increased during endurance exercise, and the pattern of MAPK activation is similar to the one observed after heparin injection. Taken together, our data strongly suggest that NEFA play a role in MAPK activation and that TLR plays a critical role in this activation.

Another potential confounding factor is the role of nonmuscle cells in the observed results. The activation of the same pathways both by endurance exercise and by heparin injection suggests that the muscle cells are likely responsible for the observed effects, even if we may not rule out a contribution of other cell types such as immune cells.

In separate experiments, we attempted to block lipolysis during exercise by injecting various doses of acipimox or nicotinic acid (13) (data not shown). We did not succeed in reducing the increase in NEFA plasma concentration without affecting significantly the exercise capacity of animals. This is a limitation of our study.

Cooperation between TLR2 and TLR4. Cooperation between TLR 2 and TLR 4 has been demonstrated in immune cells (23). Recognition of Mycobacterium bovis bacillus Calmette-Guérin by TLR activates MAPK. This activation is completely blocked by anti-TLR2 monoclonal antibody (MAb) or anti-TLR4 MAb, indicating that simultaneous recognition of Mycobacterium bovis bacillus Calmette-Guérin by TLR2 and TLR4 is required to activate MAPK (23). The results of the present study extend our knowledge of the activation of p38 MAPK and JNK by extracellular NEFA in skeletal muscle. Whatever the mechanism by which extracellular NEFA were increased, i.e., endurance exercise or heparin injection, the phosphorylation state of p38 MAPK and JNK was largely repressed in $t l r 2^{-1-}$ and in $t l r 4^{-1-}$ animals, indicating that recognition of NEFA by both TLR2 and TLR4 is necessary to activate p38 MAPK and JNK.

Exercise is known to activate the ERK1/2 pathway in an intensity-dependent manner (39). In the present study, the endurance exercise protocol was primarily designed to increase plasma NEFA concentrations (34). It did not change the phosphorylation state of ERK1/2, either in WT or in tlr $2^{-/-}$or in $t l r 4^{-/-}$animals, suggesting that the intensity of our exercise protocol was likely too low to stimulate ERK1/2. Moreover, ERK1/2 phosphorylation was not changed by heparin injection. Therefore, our results do not support the hypothesis of an activation of ERK1/2 initiated by extracellular NEFA during endurance exercise.

Lack of NF- $\boldsymbol{k B}$ pathway activation. TLR4 is known to mediate the activation of the NF- $\kappa \mathrm{B}$ pathway by longchain unsaturated fatty acids in preadipocytes in culture and by lipid infusion in mice (33). It has also been shown that the activation of the NF- $\kappa \mathrm{B}$ pathway by palmitate is repressed when TLR2 is blocked by anti-TLR2 MAb or by small-interfering RNA (32). We were unable to detect changes in the phosphorylation state of IKK $\alpha / \beta$ after endurance exercise and after heparin injection, although plasma NEFA concentration was increased. To ensure that we did not miss any activation of the NF- $\kappa$ B pathway, we measured the DNA binding of the NF- $\kappa \mathrm{B}$ and injected some animals with LPS as a positive control. These results convince us that our experimental running protocols did not induce any activation of the NF- $\kappa$ B pathway, possibly because extracellular lipid levels were not high enough and/or because the stimulation was too short. Our results are in agreement with those reported by McKenzie and Goldfarb (22), who did not observe any activation of the NF- $\kappa$ B pathway during endurance exercise in rats. 
Metabolism regulation. Transgenic animals used in this study $(17,24)$ were not muscle conditional knockout mice. The higher plasma NEFA concentrations observed after exercise in $t l r 2^{-/-}$and $t l r 4^{-/-}$animals suggest that TLR2 and TLR4 could also regulate metabolic functions in organs such as adipose tissue or modify the repartition of energy substrates used during exercise. This does not challenge the main findings of our study because circulating NEFA concentrations after exercise were higher in TLR-deficient mice compared with WT mice. These observations open new research perspectives regarding the role of TLR2 and TLR4 in various tissues during exercise.

HSP70 is one of many ligands recognized by both TLR2 and TLR4 (2). Plasma HSP70 concentrations were not changed during our exercise protocol, indicating that HSP70 does not interfere with the proposed mechanisms of activation of p38 MAPK and JNK. The question if HSP70 increases after exercise is controversial. An increase in HSP70 after exercise has been observed both in animals $(21,31)$ and in humans (37), but contradictory findings exist (19). These controversial results may be explained by the fact that HSP70 production after exercise is intensity de-

\section{REFERENCES}

1. Akira S, Sato S. Toll-like receptors and their signaling mechanisms. Scand J Infect Dis. 2003;35(9):555-62.

2. Asea A, Rehli M, Kabingu E, et al. Novel signal transduction pathway utilized by extracellular HSP70: role of toll-like receptor (TLR) 2 and TLR4. J Biol Chem. 2002;277(17):15028-34.

3. Boppart MD, Aronson D, Gibson L, et al. Eccentric exercise markedly increases c-Jun $\mathrm{NH}(2)$-terminal kinase activity in human skeletal muscle. J Appl Physiol. 1999;87(5):1668-73.

4. Chambers MA, Moylan JS, Smith JD, Goodyear LJ, Reid MB. Stretch-stimulated glucose uptake in skeletal muscle is mediated by reactive oxygen species and p38 MAP-kinase. J Physiol. 2009; 587(Pt 13):3363-73.

5. Chan MH, McGee SL, Watt MJ, Hargreaves M, Febbraio MA Altering dietary nutrient intake that reduces glycogen content leads to phosphorylation of nuclear p38 MAP kinase in human skeletal muscle: association with IL-6 gene transcription during contraction. FASEB J. 2004;18(14):1785-7.

6. Cho YY, Tang F, Yao K, et al. Cyclin-dependent kinase-3-mediated c-Jun phosphorylation at Ser63 and Ser73 enhances cell transformation. Cancer Res. 2009;69(1):272-81.

7. Civitarese AE, Hesselink MK, Russell AP, Ravussin E, Schrauwen $P$. Glucose ingestion during exercise blunts exercise-induced gene expression of skeletal muscle fat oxidative genes. Am J Physiol Endocrinol Metab. 2005;289(6):E1023-9.

8. Clerk A, Fuller SJ, Michael A, Sugden PH. Stimulation of "stressregulated" mitogen-activated protein kinases (stress-activated protein kinases/c-Jun N-terminal kinases and p38-mitogen-activated protein kinases) in perfused rat hearts by oxidative and other stresses. J Biol Chem. 1998;273(13):7228-34.

9. Connor WE, Armstrong ML. Plasma lipoprotein lipase after subcutaneous heparin. Circulation. 1961;24:87-93.

10. Deldicque L, Atherton P, Patel R, et al. Decrease in Akt/PKB signalling in human skeletal muscle by resistance exercise. Eur $J$ Appl Physiol. 2008;104(1):57-65. pendent (25). Our exercise protocol could be intense enough to promote an increment in plasma NEFA concentrations but not to increase HSP70 production.

\section{CONCLUSIONS}

This study is the first to provide evidence that during endurance exercise, TLR2 and TLR4 mediate a signal linking the elevated plasma NEFA concentrations to the activation of p38 MAPK, JNK, and c-Jun. Further research is warranted to elucidate the molecular intermediates between TLR2/TLR4 and MAPK in skeletal muscle.

Hermann Zbinden Foncea is supported by the Commission for Development Cooperation of Université Catholique de Louvain. At the time of the data collection, Louise Deldicque was a postdoctoral researcher from the Fonds de la Recherche Scientifique-Fonds $\mathrm{Na}$ tional de la Recherche Scientifique.

This study was granted by the Fonds Spéciaux de Recherche of Université Catholique de Louvain and the Association Française contre les Myopathies.

The authors thank Daniel Theisen for revising the writing of this article.

The authors have no conflict of interest.

The results of the present study do not constitute endorsement by the American College of Sports Medicine.
11. Durham WJ, Li YP, Gerken E, et al. Fatiguing exercise reduces DNA binding activity of NF-kappaB in skeletal muscle nuclei. $J$ Appl Physiol. 2004;97(5):1740-5.

12. Erridge C, Samani NJ. Saturated fatty acids do not directly stimulate Toll-like receptor signaling. Arterioscler Thromb Vasc Biol. 2009;29(11):1944-9.

13. Fuccella LM, Goldaniga G, Lovisolo $P$, et al. Inhibition of lipolysis by nicotinic acid and by acipimox. Clin Pharmacol Ther. 1980; 28(6):790-5.

14. Hayashi T, Hirshman MF, Dufresne SD, Goodyear LJ. Skeletal muscle contractile activity in vitro stimulates mitogenactivated protein kinase signaling. Am J Physiol. 1999;277(4 Pt 1): C701-7.

15. Ho RC, Hirshman MF, Li Y, et al. Regulation of IkappaB kinase and NF-kappaB in contracting adult rat skeletal muscle. $A m J$ Physiol Cell Physiol. 2005;289(4):C794-801.

16. Hoeks J, van Baak MA, Hesselink MK, et al. Effect of beta1- and beta2-adrenergic stimulation on energy expenditure, substrate oxidation, and UCP3 expression in humans. Am J Physiol Endocrinol Metab. 2003;285(4):E775-82.

17. Hoshino K, Takeuchi O, Kawai T, et al. Cutting edge: Toll-like receptor 4 (TLR4)-deficient mice are hyporesponsive to lipopolysaccharide: evidence for TLR4 as the Lps gene product. J Immunol. 1999;162(7):3749-52.

18. Kramer HF, Goodyear LJ. Exercise, MAPK, and NF-kappaB signaling in skeletal muscle. J Appl Physiol. 2007;103(1):388-95.

19. Liu Y, Lormes W, Wang L, Reissnecker S, Steinacker JM. Different skeletal muscle HSP70 responses to high-intensity strength training and low-intensity endurance training. Eur J Appl Physiol. 2004;91(2-3):330-5.

20. Livesey JH. Kurtosis provides a good omnibus test for outliers in small samples. Clin Biochem. 2007;40(13-14):1032-6.

21. Locke M, Noble EG, Atkinson BG. Exercising mammals synthesize stress proteins. Am J Physiol. 1990;258(4 Pt 1):C723-9. 
22. McKenzie MJ, Goldfarb AH. Aerobic exercise bout effects on gene transcription in the rat soleus. Med Sci Sports Exerc. 2007; 39(9):1515-21.

23. Mendez-Samperio P, Belmont L, Miranda E. Mycobacterium bovis BCG Toll-like receptors 2 and 4 cooperation increases the innate epithelial immune response. Arch Med Res. 2008;39(1):33-9.

24. Michelsen KS, Aicher A, Mohaupt M, et al. The role of Toll-like receptors (TLRs) in bacteria-induced maturation of murine dendritic cells (DCS). Peptidoglycan and lipoteichoic acid are inducers of DC maturation and require TLR2. J Biol Chem. 2001; 276(28):25680-6.

25. Milne KJ, Noble EG. Exercise-induced elevation of HSP70 is intensity dependent. $J$ Appl Physiol. 2002;93(2):561-8.

26. Morton JP, Holloway K, Woods P, et al. Exercise training-induced gender-specific heat shock protein adaptations in human skeletal muscle. Muscle Nerve. 2009;39(2):230-3.

27. Poltorak A, He X, Smirnova I, et al. Defective LPS signaling in $\mathrm{C} 3 \mathrm{H} / \mathrm{HeJ}$ and $\mathrm{C} 57 \mathrm{BL} / 10 \mathrm{ScCr}$ mice: mutations in Tlr4 gene. Science. 1998;282(5396):2085-8.

28. Racay P, Gregory P, Schwaller B. Parvalbumin deficiency in fasttwitch muscles leads to increased 'slow-twitch type' mitochondria, but does not affect the expression of fiber specific proteins. FEBS J. 2006;273(1):96-108.

29. Renard P, Ernest I, Houbion A, et al. Development of a sensitive multi-well colorimetric assay for active NFkappaB. Nucleic Acids Res. 2001;29(4):E21.

30. Reyna SM, Ghosh S, Tantiwong P, et al. Elevated toll-like receptor 4 expression and signaling in muscle from insulin-resistant subjects. Diabetes. 2008;57(10):2595-602.

31. Samelman TR. Heat shock protein expression is increased in cardiac and skeletal muscles of Fischer 344 rats after endurance training. Exp Physiol. 2000;85(1):92-102.
32. Senn JJ. Toll-like receptor- 2 is essential for the development of palmitate-induced insulin resistance in myotubes. $J$ Biol Chem. 2006;281(37):26865-75.

33. Shi H, Kokoeva MV, Inouye K, Tzameli I, Yin H, Flier JS. TLR4 links innate immunity and fatty acid-induced insulin resistance. $J$ Clin Invest. 2006;116(11):3015-25.

34. Stich V, de Glisezinski I, Berlan M, et al. Adipose tissue lipolysis is increased during a repeated bout of aerobic exercise. $J$ Appl Physiol. 2000;88(4):1277-83.

35. Tunstall RJ, McAinch AJ, Hargreaves M, van Loon LJ, CameronSmith D. Reduced plasma free fatty acid availability during exercise: effect on gene expression. Eur J Appl Physiol. 2007;99(5): 485-93.

36. van Ginneken MM, de Graaf-Roelfsema E, Keizer HA, et al. Effect of exercise on activation of the p38 mitogen-activated protein kinase pathway, c-Jun $\mathrm{NH}_{2}$ terminal kinase, and heat shock protein 27 in equine skeletal muscle. Am J Vet Res. 2006;67(5): $837-44$.

37. Walsh RC, Koukoulas I, Garnham A, Moseley PL, Hargreaves M, Febbraio MA. Exercise increases serum Hsp72 in humans. Cell Stress Chaperones. 2001;6(4):386-93.

38. Widegren U, Jiang XJ, Krook A, et al. Divergent effects of exercise on metabolic and mitogenic signaling pathways in human skeletal muscle. FASEB J. 1998;12(13):1379-89.

39. Widegren U, Wretman C, Lionikas A, Hedin G, Henriksson J. Influence of exercise intensity on ERK/MAP kinase signalling in human skeletal muscle. Pflugers Arch. 2000;441(2-3):317-22.

40. Wright DC, Geiger PC, Han DH, Jones TE, Holloszy JO. Calcium induces increases in peroxisome proliferator-activated receptor gamma coactivator-1alpha and mitochondrial biogenesis by a pathway leading to $\mathrm{p} 38$ mitogen-activated protein kinase activation. J Biol Chem. 2007;282(26):18793-9. 